\title{
Concentrate for Solution for Injection Dosage Form
}

National Cancer Institute

\section{Source}

National Cancer Institute. Concentrate for Solution for Injection Dosage Form. NCI

Thesaurus. Code C149402.

Liquid sterile preparation intended to be diluted in the specified liquid to obtain a solution for injection. 